\title{
THE NAIL-FOLD CAPILLARIES IN COARCTATION OF THE AORTA
}

\author{
BY \\ S. SPENCE MEIGHAN \\ From the Western District Hospital, Glasgow \\ Received September 22, 1955
}

While the role of the capillary in hypertension in man is not known, mainly owing to technical difficulties, Scheinker (1948), using histological methods, found that in arterial hypertension the early stages of cerebral vascular damage were confined to the capillaries which showed proliferative and degenerative changes. The existence of a hypertensive capillary pattern in the bulbar conjunctiva has been described by Lack et al. (1949). These capillary changes consisted of generalized narrowing of the lumen, elongation with angular tortuosities, abnormal coiling, looping, and occasionally sacculations, and their severity could be directly correlated with the height of the diastolic blood pressure. Lee and Holze (1951) found similar capillary changes in the bulbar conjunctiva of hypertensive patients. In spite of these findings, Goldblatt (1951) stated that it had been impossible to arrive at any conclusion about the causative relationship between the changes in the capillaries and hypertension.

The capillaries of the finger nail-fold of patients with hypertension were observed by Boas (1921) to have a greatly accelerated rate of blood flow. Brown and Roth (1927) found no characteristic morphology in essential hypertension although there was an increased tortuosity of the loops as compared with the normal for the age group: rapid alternation of fast and slow rates of blood flow were observed frequently. Weiss and Frazier (1930) noted irregularity of the loops and the frequent occurrence of a narrowed, hair-like arterial limb. Wright and Duryee (1933) stated that while much increase of blood pressure was often associated with an increased tortuosity of the nail-fold capillaries, there were many exceptions to the rule. Greisman (1954) noted that the rate of blood flow was usually rapid in essential hypertension and in hypertension induced by lævonoradrenaline administration.

Lombard (1912) was the first to observe the capillaries of the living nail-fold. If oil be placed on the skin of the nail-fold and it be examined under a microscope, hair-pin shaped capillary loops are seen lying parallel to the skin surface. These loops are arranged in palisades of which there may be two, three, or four. The capillaries appear bright red against a background of pink, and the arterial limb of the loop is narrower than the venous limb. The identity of the limbs can be established by observation of the direction of blood flow within them. The rate of blood flow may be observed but its measurement is difficult. It is almost always possible to obtain a clear view of the capillary loops and dimly to see the sub-papillary plexuses.

The appearance of these capillaries even in normal persons is subject to wide variation. Roth (1946) stated that it had been impossible to establish a single standard type of normal nail-fold capillary. The appearance of the capillaries changes with age. Mayer (1921) in a study of the capillaries of the new-born, found an irregular branching network close to the skin surface. By the age of six months, the adult pattern of capillary loops was usually established, and an increased length and incidence of tortuous loops with advancing age was found by Roth (1946).

While the capillaries of the nail-fold of the toes have not been studied as intensively as those of the fingers, they have a similar morphological pattern. The skin tends to be thicker over the toes, thus hindering observation. In my experience, the capillaries of the toes are usually considerably smaller than those of the fingers. 
It is difficult to know what capillary changes to ascribe to disease when the normal pattern of the capillaries can vary so much from one person to another.

Al

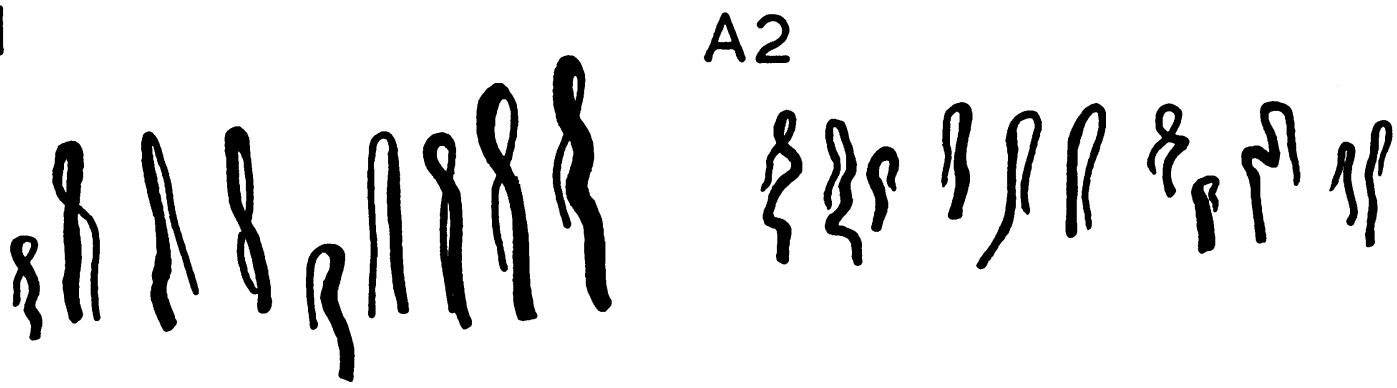

$\mathrm{BI}$
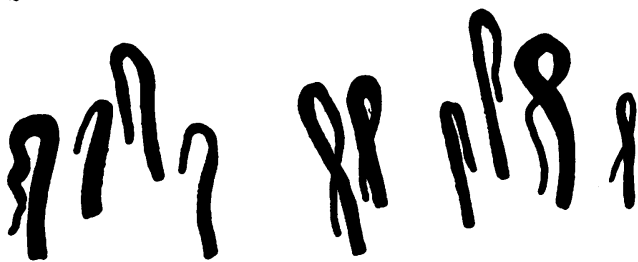

B2

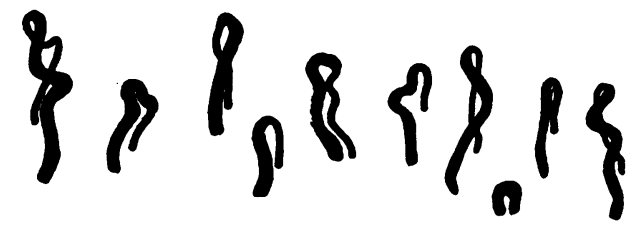

$\mathrm{Cl}$

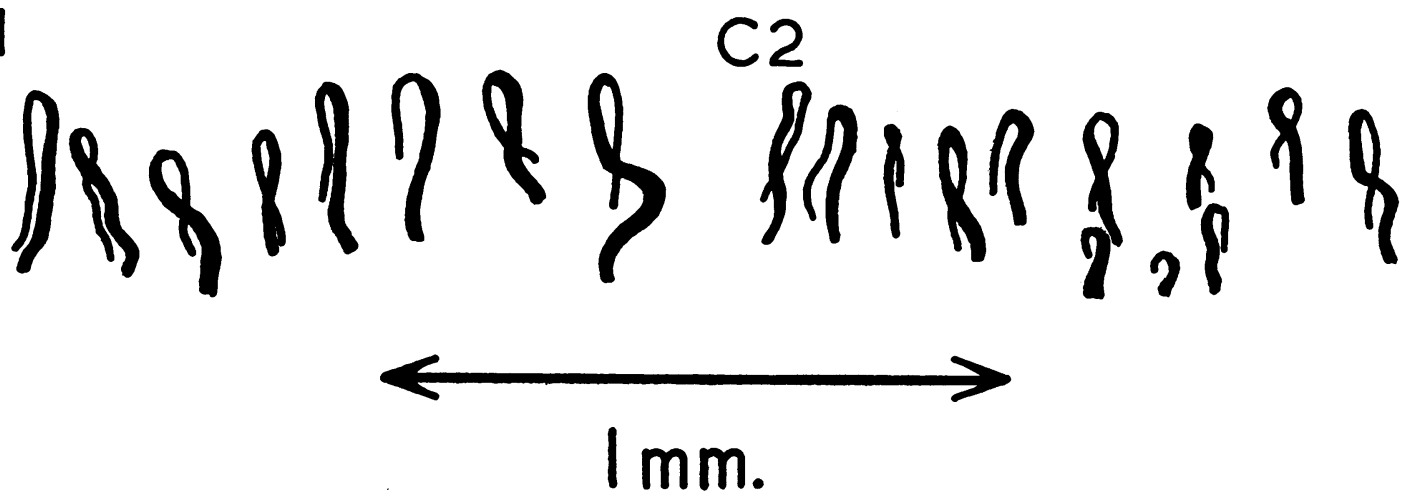

FiG. 1.-Tracings of microphotographs of the capillary loops of the fingers on the left, and of the toes, on the right.

(A) In a normal subject.

(B) In Case 1; and (C) in Case 2.

\section{ObJeCt AND Method Of THIS STUdy}

The present study was undertaken to determine whether there was a significant difference between the appearance of the nail-fold capillaries in the fingers and the toes of patients with coarctation of the aorta. In this congenital malformation, the blood pressure is increased in the upper part of the body and decreased in the lower part. This condition affords the opportunity of studying the periphery of an arterial tree, subjected to a wide difference in blood pressure, in separate sites, within the same individual. It therefore seemed to be appropriate to find out whether there was a variation in the degree of tortuosity of the capillaries in the upper and lower limbs in a series of patients with coarctation of the aorta.

$2 \mathrm{~K}$ 
Method. A Watson Service microscope had a sheet of metal incorporated into the movable stage, and upon it plasticine was moulded. The digit to be examined was introduced into a groove made in the plasticine, which was then gently pressed around to provide a degree of fixation compatible with integrity of the circulation. A drop of glycerin was placed over the nail-fold and a coverslip balanced upon it to reduce the surface reflection of light. The illumination was provided by a powerful tungsten filament lamp in an Edison lamphouse. With a 1.5-in. objective glass and a $\times 10$ eyepiece magnification of about forty diameters was obtained. With this optical arrangement a wide area could be studied and the overall pattern of the capillaries observed. For a more detailed study of individual capillaries, and for assessment of the rate of blood flow, a 16-mm. objective glass was used in conjunction with the same eyepiece, giving an approximate magnification of a hundred diameters.

For microphotography, a $35-\mathrm{mm}$. eyepiece camera was used in conjunction with an electronic flash of a hundred Joules output. This apparatus gave an effective exposure of about onethousandth of a second.

Material. The capillaries of the finger and toe nail-fold were examined in fifteen normal subjects and in four patients with coarctation of the aorta. The patients with coarctation were males of 10,17, 21, and 35 years. The subjects of the control series were of similar ages. Each patient with aortic coarctation had brachial hypertension and none had a recordable blood pressure in the legs. All had arterial collateral circulation. In one patient who died after operation aortic coarctation was confirmed at autopsy.

\section{RESULTS}

Microphotographs of the finger and toe nail-fold capillaries of each of the patients with coarctation of the aorta were taken and tracings from these are shown together with those of one normal subject. These illustrations are taken as confirming the finding on direct observation, that in no case of aortic coarctation did the degree of tortuosity of the finger capillaries exceed that of the toes. The rate and nature of blood flow, as judged by direct observation, seemed to be identical. The toe capillaries in coarctation of the aorta were smaller than the finger capillaries but not by an amount more than that seen in the control series.

\section{SUMMARY AND CONCLUSIONS}

The capillaries of the nail-fold of fingers and toes were examined in four patients with coarctation of the aorta and in fifteen normal subjects. In the two groups examined, no significant differences were found.

Elevation of the blood pressure alone does not, therefore, cause any change in the morphology of the cutaneous capillaries of the nail-fold of the fingers.

No information of value in diagnosis is to be obtained from examination of the nail-fold of the fingers and toes in patients with coarctation of the aorta.

The investigation was made possible by grants from the W. H. Ross Foundation (Scotland) and the Scottish Advisory Committee for Medical Research.

\section{REFERENCES}

Boas, E. P. (1922). Med. Clin. N. Amer., 5, 1007.

Brown, G. E., and Roth, G. M. (1927). Med. J. Aust., 1, 499.

Goldblatt, H. (1951). In Bell, E. T., Hypertension-A Symposium. University of Minnesota Press.

Greisman, S. E. (1954). J. clin. Invest., 33, 975.

Lack, A., Adolph, W., Ralston, W., Leiby, G., Winsor, T., and Griffith, G. (1949). Amer. Heart J., $38,654$.

Lee, R. E., and Holze, E. A. (1951). J. clin. Invest., 30, 539.

Lombard, W. P. (1912). Amer. J. Physiol., 29, 335.

Mayer, K. M. (1921). Amer. J. Dis. Child., 22, 381.

Roth, G. M. (1946). In Peripheral Vascular Diseases, by Allen, Barker, and Hines. W. B. Saunders Company, Philadelphia.

Scheinker, I. M. (1948). Amer. J. Path., 24, 211.

Weiss, S., and Frazier, W. R. (1930). Amer. Heart J., 5, 511.

Wright, I. S., and Duryee, A. W. (1933). Arch. intern. Med., 52, 545. 